\title{
Synthesis, Electrochemistry and Spectroscopic Properties of Ruthenium Phthalocyanine and Naphthalocyanine Complexes with Triphenylarsine Ligands
}

\author{
Tristan Rawling, ${ }^{[\mathrm{a}]}$ Andrew M. McDonagh, ${ }^{[\mathrm{a}]}$ and Stephen B. Colbran ${ }^{[\mathrm{b}]}$
}

Keywords: Ruthenium / Phthalocyanine / Naphthalocyanine / Arsine / Electrochemistry

We present here the preparation of $\left[\mathrm{PcRu}\left(\mathrm{AsPh}_{3}\right)_{2}\right]$ (1) and $\left[\left\{(t \mathrm{Bu})_{4} \mathrm{Nc}\right\} \mathrm{Ru}\left(\mathrm{AsPh}_{3}\right)_{2}\right]$ (2). These complexes are the first examples of metal phthalocyanine and naphthalocyanine complexes with axially-coordinated arsine ligands. Both complexes were characterised by spectroscopic methods. The $\mathrm{AsPh}_{3}$ ligands readily dissociate in non-coordinating solvents, with 2 showing more rapid dissociation. The electrochemistry of the complexes was studied by cyclic voltammetry. Complex 1 displayed one reduction and two oxidation processes. All three processes are macrocycle centred. The redox behaviour of $\mathbf{1}$ is similar to that of ruthenium phthalocyanine complexes with pyridyl ligands. One reduction and three oxidation processes were observed for complex 2. The reduction and first oxidation are assigned to macrocycle centred processes. The UV-Vis spectra of both complexes recorded over time showed macrocycle-centred oxidation. The oxidation was hindered by degassing the solvent or adding excess $\mathrm{AsPh}_{3}$ to the solution. We were not able to determine if the species being oxidised are the starting complexes, or if ligand dissociation leads to an easily oxidised five coordinate species.

(C) WILEY-VCH Verlag GmbH \& Co. KGaA, 69451 Weinheim, Germany, 2007) [a] Institute of Nanoscale Technology University of Technology Sydney Sydney, NSW 2007, Australia

Đ Fax: +61295141717

E-mail: andrew.mcdonagh@uts.edu.au

[b] School of Chemistry

The University of New South Wales Sydney, NSW 2052, Australia

Supporting information for this article is available on the WWW under http://www.eurjic.org/ or from the author.

\section{Introduction}

We present the first examples of ruthenium phthalocyanine and naphthalocyanine complexes bearing arsine ligands (see Figure 1) together with an examination of their electrochemical and spectroscopic properties.

Ruthenium phthalocyanine complexes have been investigated as sensitisers in photodynamic therapy (PDT) ${ }^{[1,2]}$ and photovoltaic devices, ${ }^{[3-5]}$ as catalysts in oxidation, ${ }^{[6-8]}$ reduction, ${ }^{[9-11]}$ hydrogenation, ${ }^{[12]}$ and cyclopropanation reactions, ${ }^{[13]}$ as gas sensing thin films, ${ }^{[14]}$ and as organic conductors. ${ }^{[15,16]}$ Despite the close structural similarity, ruthenium naphthalocyanine complexes have attracted much less attention. Their use as sensitisers in $\mathrm{PDT}^{[17]}$ and as organic conductors ${ }^{[16,18]}$ has been reported.

The versatility of these complexes is due in most part to their redox properties, intense electronic absorption bands and stability, which can be significantly perturbed and advantageously manipulated by subtle changes to the axial ligands. ${ }^{[19]}$ Most of the reported complexes of ruthenium phthalocyanine and naphthalocyanine have $\mathrm{N}$-donor axial ligands, e.g., pyridine, pyrazine and quinoline derivatives. ${ }^{[20]}$ Bridging N-donor ligands such as pyrazine have been used to prepare conducting oligomers $^{[21]}$ and pyridines with carboxylic acid functional groups have been utilized as anchoring ligands in photovoltaic devices. ${ }^{[3,4]}$ Complexes where the axial ligands contain phosphorus donor atoms have been reported. $\mathrm{K}_{2}\left[\mathrm{PcRu}\left\{\mathrm{Ph}_{2} \mathrm{P}\left(3-\mathrm{C}_{6} \mathrm{H}_{4} \mathrm{SO}_{3}\right)\right\}_{2}\right]^{[1,2]}$ and $\mathrm{K}_{2}\left[\mathrm{NcRu}\left\{\mathrm{PhP}\left(3-\mathrm{C}_{6} \mathrm{H}_{4} \mathrm{SO}_{3}\right)\right\}_{2}\right]^{[17]}$ (where Pc = phthalocyanine, Nc $=$ naphthalocyanine) were prepared and investigated as sensitisers in PDT. To date, no metal phthalocyanine or naphthalocyanine complexes bearing arsine ligands have been reported although two examples of ruthenium porphyrin complexes with triphenylarsine axial ligands appear in the literature. $\mathrm{AsPh}_{3}$ was found to react with [(TTP) $\mathrm{Ru}(\mathrm{CO})(\mathrm{EtOH})]$ (where TTP = tetraphenylporphyrin) to form [(TTP) Ru( $\left.\left(\mathrm{AsPh}_{3}\right)_{2}\right]{ }^{[22]}$ Reacting $\mathrm{AsPh}_{3}$ with the $\pi$-cation radical $\left[(\mathrm{OEP})^{+} \mathrm{Ru}^{\mathrm{II}}(\mathrm{CO})\right]^{+}$gave $\left[(\mathrm{OEP}) \mathrm{Ru}^{\mathrm{III}}\left(\mathrm{AsPh}_{3}\right)_{2}\right]^{+}$(where $\mathrm{OEP}=$ octaethylporphyrin). ${ }^{[23]}$

We show here that the properties of the arsine-substituted ruthenium phthalocyanine and naphthalocyanine complexes differ significantly from those of the ruthenium porphyrin-arsine complexes.

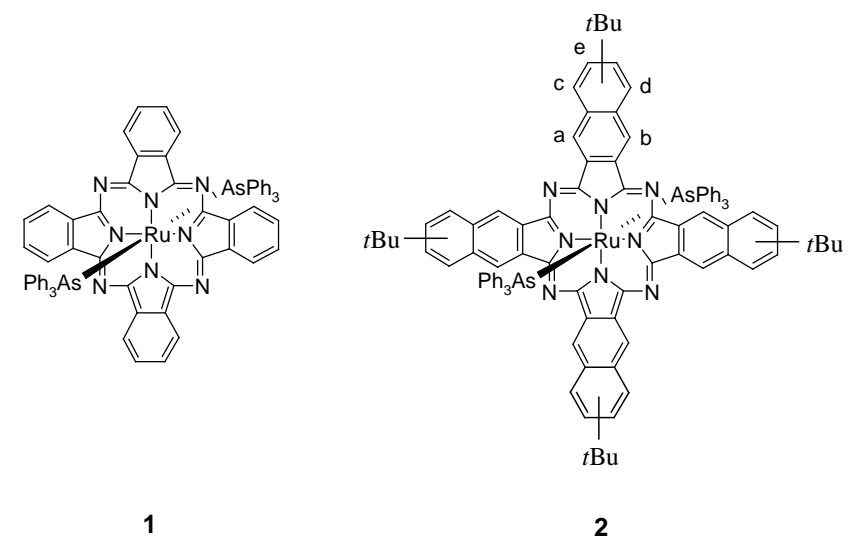

Figure 1. $\left[\mathrm{PcRu}\left(\mathrm{AsPh}_{3}\right)_{2}\right](\mathbf{1})$ and $\left[\left\{(\mathrm{Bu})_{4}-2,3-\mathrm{Nc}\right\} \mathrm{Ru}\left(\mathrm{AsPh}_{3}\right)_{2}\right]$ (2).

\section{Results and Discussion}

Synthesis 
Complexes $\mathbf{1}$ and $\mathbf{2}$ were prepared using adaptations of the methods of Brooks et al. ${ }^{[17,24]}$ The synthesis of $\mathbf{2}$ is shown in Scheme 1 . The bis-ammine complexes $\left[\mathrm{PcRu}\left(\mathrm{NH}_{3}\right)_{2}\right]$ and $\left[\left\{(t \mathrm{Bu})_{4-}\right.\right.$ 2,3-Nc $\mathrm{Ru}\left(\mathrm{NH}_{3}\right)_{2}$ ] were prepared by the reaction of phthalonitrile or 6-t-butyl-2,3-naphthalonitrile with $\mathrm{RuCl}_{3} \cdot 3 \mathrm{H}_{2} \mathrm{O}$ and ammonia in refluxing pentanol. Reaction of the bis-ammine complexes with benzonitrile gave the corresponding bis-benzonitrile complexes. The lability of the benzonitrile ligands makes these complexes suitable starting materials for the preparation of other axially substituted complexes.

Exchange of the axial benzonitrile ligands was achieved using a slight molar excess of triphenylarsine in refluxing dichloromethane under an inert atmosphere. Replacement of the benzonitrile ligands (as monitored by thin-layer chromatography) was complete in four hours.

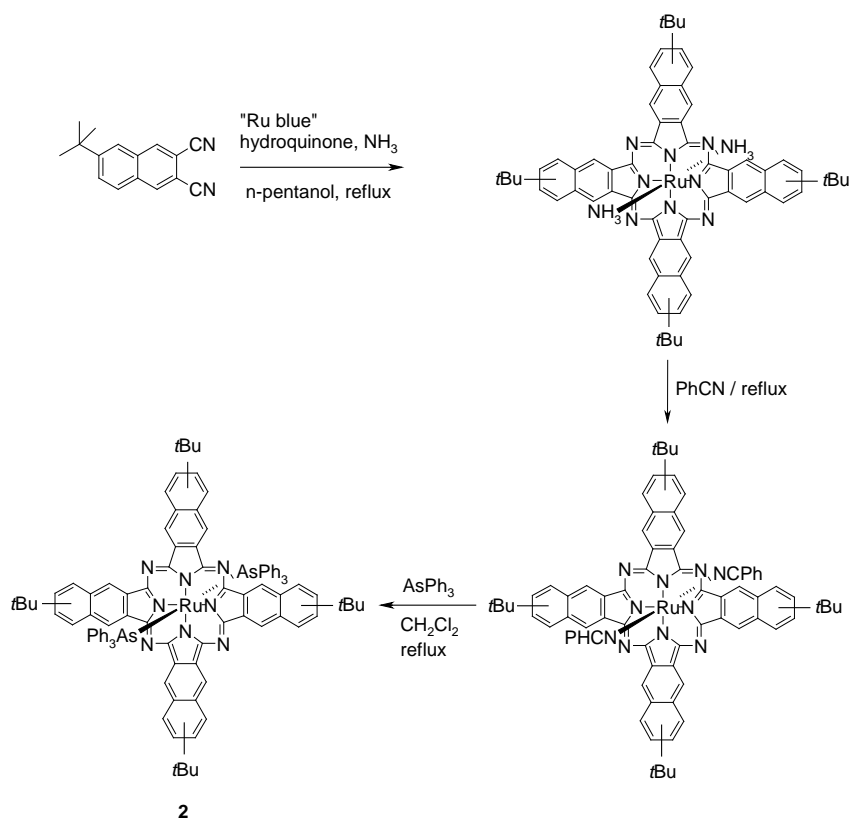

Scheme 1. Synthesis of $\left[\left\{(t \mathrm{Bu})_{4}-2,3-\mathrm{Nc}\right\} \operatorname{Ru}\left(\mathrm{AsPh}_{3}\right)_{2}\right](2)$.

\section{${ }^{1}$ H NMR spectroscopy}

Figure 2 shows the ${ }^{1} \mathrm{H}$ NMR spectrum of complex 1 . The macrocyclic protons appear as two AA'BB' patterns at $\delta 8.95$ and 7.81 and are characteristic of metal phthalocyanine complexes lacking peripheral substitution ${ }^{[25-27]}$ and similar to those observed for the complex $\left[\mathrm{PcRu}\left(\mathrm{PPh}_{3}\right)_{2}\right]$ at $\delta 8.83$ and $7.72 \square^{28]}$

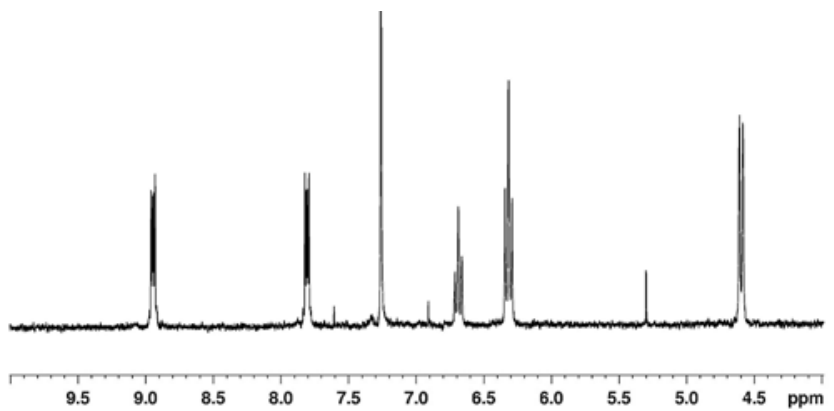

Figure 2. ${ }^{1} \mathrm{H}$ NMR spectrum of $\mathbf{1}(0.8 \mathrm{mM})$ in $\mathrm{CDCl}_{3}$.
The ${ }^{1} \mathrm{H}$ NMR spectrum of $\mathrm{AsPh}_{3}$ in $d$-chloroform has a single broad resonance at $\delta$ 7.34. In contrast, the coordinated ligand displays three distinct resonances significantly shifted upfield at $\delta$ 4.59, 6.32, and 6.69 (Figure 2). The ortho-phenyl protons will experience the greatest shielding due to macrocyclic diamagnetic ring currents ${ }^{[18,27,29]}$ and thus the signal at $\delta 4.59$ is assigned to the twelve ortho-protons of the coordinated ligands. The signals at $\delta$ 6.32 and 6.69 are assigned to the meta- and para-phenyl protons, respectively.

In the ${ }^{1} \mathrm{H}$ NMR spectrum of $\mathbf{2}$, five signals assigned to the macrocyclic protons are observed corresponding to the five nonequivalent macrocyclic proton environments. These signals are broadened and poorly resolved in comparison with those of $\mathbf{1}$ as the ring-substituted complex exists as a mixture of four positional isomers, ${ }^{[20]}$ which we were unable to separate. Signals assigned to the protons "a" and "b" (Figure 1) are observed at $\delta 9.47$ and 9.43 while those assigned to "c" and " $\mathrm{d}$ " overlap at $\delta 8.40$. Signals arising from protons " $\mathrm{e}$ ", furthest from the ruthenium metal centre, are observed at $\delta 7.87$. The macrocyclic protons, in particular "a" and " $\mathrm{b}$ ", where the influence of the axial ligands is greatest, are shifted upfield compared to analogous complexes bearing aromatic $\mathrm{N}$-heterocyclic axial ligands ${ }^{[16,29,30]}$ such as pyridine and quinoline. This trend is also observed in the spectrum of $\mathbf{1}$ and indicates that the $\mathrm{AsPh}_{3}$ ligand is more electron donating than the $\mathrm{N}$-heterocyclic ligands.

The same pattern of axial $\mathrm{AsPh}_{3}$ resonances is observed in the spectrum of complex 2, however the extent of the shielding is less than for the phthalocyanine complex. The weaker shielding of ruthenium naphthalocyanine complexes has been documented previously. ${ }^{[18]}$

Also observed in the ${ }^{1} \mathrm{H}$-NMR spectrum of a freshly prepared $\mathrm{CDCl}_{3}$ solution of $\mathbf{2}$ is a singlet at $\delta 7.34$, which is assigned to free $\mathrm{AsPh}_{3}$. Integration of the spectrum revealed that at a concentration of $8 \mathrm{mM}$, the amount of free $\mathrm{AsPh}_{3}$ is $\sim 8 \%$ relative to the parent complex and increases to $\sim 34 \%$ over a period of seventeen hours at room temperature. The amount of free $\mathrm{AsPh}_{3}$ is also dependant on concentration, with $\sim 27 \%$ of free $\mathrm{AsPh}_{3}$ observed in a freshly prepared $0.8 \mathrm{mM}$ solution. The dependence of the amount free $\mathrm{AsPh}_{3}$ on time and concentration indicates that the free $\mathrm{AsPh}_{3}$ arises from complex dissociation and is not present simply as an impurity from the synthesis. The ${ }^{1} \mathrm{H}$ NMR spectrum of $\mathbf{1}$ initially revealed no observable signals from uncoordinated $\mathrm{AsPh}_{3}$ over a concentration range of 8 to $0.8 \mathrm{mM}$. However, after seventeen hours $\sim 6 \%$ free $\mathrm{AsPh}_{3}$ is observed in an $8 \mathrm{mM}$ solution. This data suggests that the arsine ligand is more labile when coordinated to ruthenium naphthalocyanine compared to the phthalocyanine

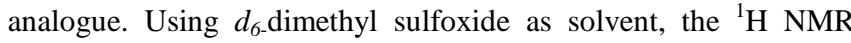
spectra of 1 and $\mathbf{2}$ show only signals for free $\mathrm{AsPh}_{3}$, indicating rapid and complete displacement of $\mathrm{AsPh}_{3}$ by dimethyl sulfoxide.

\section{Electrochemistry}

Figure 3 shows cyclic voltammograms for $\mathbf{1}$ and $\mathbf{2}$ together with that for $\mathrm{AsPh}_{3}$. Potentials quoted are relative to the $\mathrm{Fc}^{+} / \mathrm{Fc}$ couple (i.e. $\left.\mathrm{E}_{1 / 2}\left(\mathrm{Fc}^{+} / \mathrm{Fc}\right)=0 \mathrm{~V}\right)$. The cyclic voltammogram of 1 shows reversible oxidations at 0.10 and $0.92 \mathrm{~V}\left(\Delta \mathrm{E}_{\mathrm{p}} \approx 0.09 \mathrm{~V}\right.$ for both processes) and an irreversible reduction at $-1.91 \mathrm{~V}$. The difference in potential between the reduction and the first oxidation is $2.01 \mathrm{~V}$ and is similar in energy to the Q-band transition (644 nm or 1.93 $\mathrm{V})$. It can be concluded that the reduction and first oxidation are macrocycle centered processes i.e. the $\left[\mathrm{Pc}^{2-} \mathrm{Ru}^{\mathrm{II}}\right] /\left[\mathrm{Pc}^{3-} \mathrm{Ru}^{\mathrm{II}}\right]^{-}$and $\left[\mathrm{Pc}^{-} \mathrm{Ru}^{\mathrm{II}}\right]^{+} /\left[\mathrm{Pc}^{2-} \mathrm{Ru}^{\mathrm{II}}\right]$ couples respectively. This redox behaviour is similar to ruthenium phthalocyanine complexes with pyridine 
derivatives as axial ligands. ${ }^{[20]}$ With respect to a typical pyridine complex, e.g. $\left[\mathrm{PcRu}(4-m e t h y l p y r i d i n e)_{2}\right],{ }^{[31]}$ the first oxidation potential 1 occurs at $180 \mathrm{mV}$ more negative. This shift can be attributed to the electron donating $\mathrm{AsPh}_{3}$ ligand increasing the electron density within the phthalocyanine macrocycle. The potential of the second oxidation in ruthenium phthalocyanine complexes with pyridyl axial ligands, assigned as the $\left[\mathrm{Pc}^{0} \mathrm{Ru}^{\mathrm{II}}\right]^{2+} /\left[\mathrm{Pc}^{-} \mathrm{Ru}^{\mathrm{II}}\right]^{+}$couple, ranges from $0.83-0.94 \mathrm{~V}$. As the second oxidation of $\mathbf{1}$ falls within this range we also assign it to a macrocycle-centered process. The potential of the reduction falls within the range observed for ruthenium phthalocyanine complexes with pyridyl axial ligands, suggesting the axial ligand may have little effect on the reduction potential.

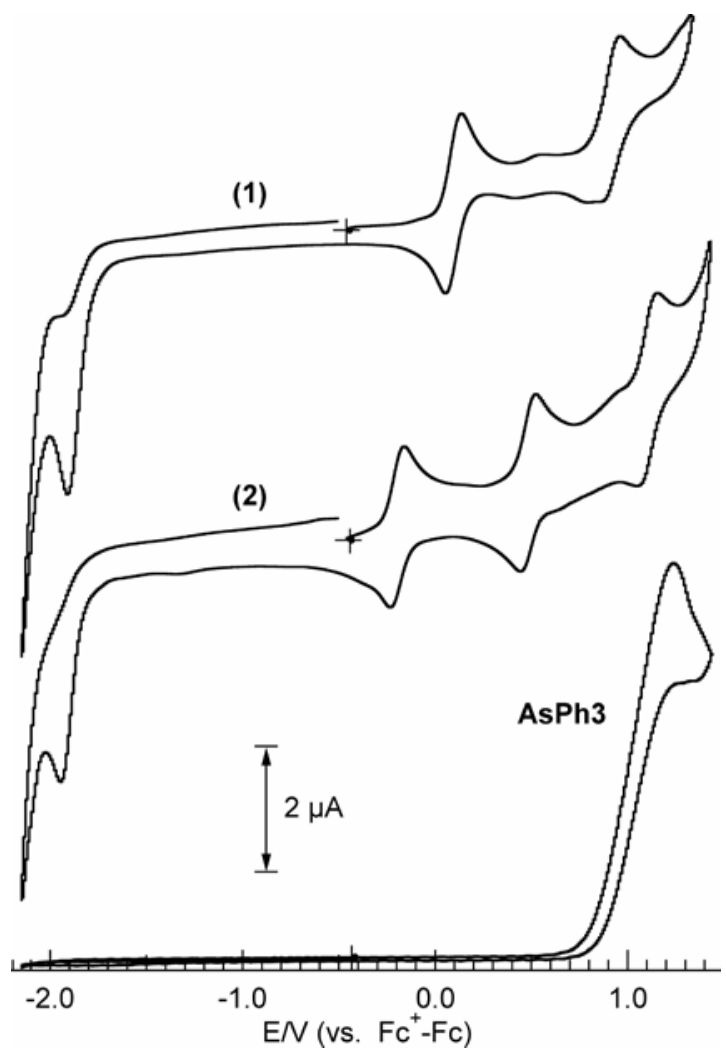

Figure 3. Cyclic voltammograms of $\mathbf{1}$ and $\mathbf{2}$ in dichloromethane solution with $0.1 \mathrm{M}\left[\mathrm{Bu}_{4} \mathrm{~N}\right]\left[\mathrm{PF}_{6}\right]$ electrolyte. Scan rate: $100 \mathrm{mV} \mathrm{s}^{-1}$.

The electrochemistry of ruthenium naphthalocyanine complexes has received very little attention, with $\left[2,3-\mathrm{NcRu}(\text { (pyridine) })_{2}\right]^{[18]}$ being the only complex for which electrochemical data has been reported. Consecutive one-electron reductions at -1.70 and $-2.16 \mathrm{~V}$, and an oxidation $0.02 \mathrm{~V}$ (in pyridine $\mathrm{vs}^{\mathrm{Fc}}{ }^{+}, \mathrm{Fc}$, original data: -1.24 $\mathrm{V},-1.70 \mathrm{~V}, 0.48 \mathrm{~V}$ vs SCE) were observed. The first reduction and oxidation were assigned to macrocycle-centered processes by comparison with the Q-band energy while the second reduction process was not assigned. In contrast, the cyclic voltammogram of a freshly-made, anaerobic solution of complex 2 in dichloromethane shows one irreversible reduction at $-1.95 \mathrm{~V}$, and three reversible oxidations at $-0.19,0.49$ and $1.10 \mathrm{~V} .\left(\Delta \mathrm{E}_{\mathrm{p}} \approx 0.08\right.$, 0.08 and $0.10 \mathrm{~V}$, respectively). The energy difference between the reduction and first oxidation $(1.76 \mathrm{~V})$ is close to the energy of the Q-band (716 $\mathrm{nm}$ or $1.73 \mathrm{~V}$ ), and these can therefore be assigned to the $\left[\mathrm{Nc}^{2-} \mathrm{Ru}^{\mathrm{II}}\right] /\left[\mathrm{Nc}^{3-} \mathrm{Ru}^{\mathrm{II}}\right]^{-}$and $\left[\mathrm{Nc}^{-} \mathrm{Ru}^{\mathrm{II}}\right]^{+} /\left[\mathrm{Nc}^{2-} \mathrm{Ru}^{\mathrm{II}}\right]$ couples, respectively. The potential of the $\left[\mathrm{Nc}^{-} \mathrm{Ru}^{\mathrm{II}}\right]^{+} /\left[\mathrm{Nc}^{2-} \mathrm{Ru}^{\mathrm{II}}\right]$ couple in 2 is shifted negative $210 \mathrm{mV}$ compared to that of [2,3-NcRu(py) $)_{2}$. This may be attributed to the electron-donating $\mathrm{AsPh}_{3}$ ligands, as well as the peripheral $t \mathrm{Bu}$ groups, which cause negative shifts in the macrocycle centered oxidation of ruthenium phthalocyanines. ${ }^{[32]}$ A second reduction was not observed for [2,3$\mathrm{NcRu}(\mathrm{py})_{2}$ ] within the potential window of dichloromethane. The second and third oxidations could not be assigned by spectroelectrochemistry due to the liability of the $\mathrm{AsPh}_{3}$ ligands, however they are not due to oxidation of free $\mathrm{AsPh}_{3}$, as this occurs at a more positive potential (see figure 3).

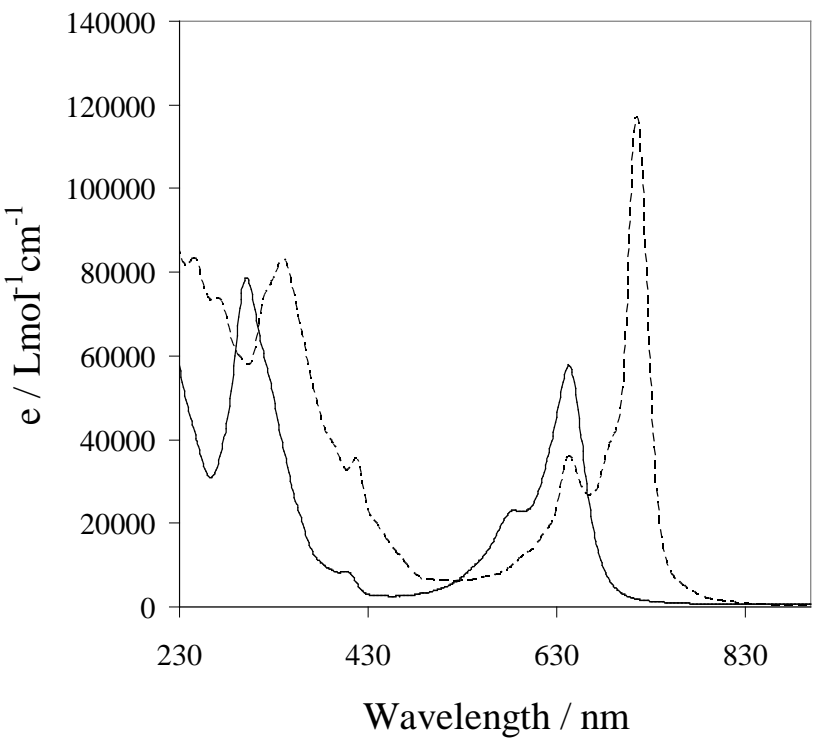

Figure 4. UV-Visible spectrum of $\mathbf{1}$ (solid line) and $\mathbf{2}$ (dashed line) in degassed dichloromethane.

\section{UV-visible spectroscopy}

The electronic spectra of $\mathbf{1}$ and $\mathbf{2}$ in degassed dichloromethane are shown in Figure 4 and are characteristic of six-coordinate ruthenium phthalocyanine and naphthalocyanine complexes. ${ }^{[20]}$ The most prominent features are the Q-bands (643 nm in 1, $716 \mathrm{~nm}$ in 2) and the Soret-bands (303 nm in 1, 340 in 2). Both transitions arise from $\pi \rightarrow \pi^{*}$ transitions within the macrocycle. The Q- and Soret-bands have shoulders in the spectra for each complex. The energy of the Q-band and it's shoulder in the electronic spectrum of $\mathbf{1}$ is very similar to that reported for $\left[\mathrm{PcRu}\left(\mathrm{PPh}_{3}\right)_{2}\right],{ }^{[28]}$ however the Soret-band of $\left[\mathrm{PcRu}\left(\mathrm{PPh}_{3}\right)_{2}\right]$ appears at $319 \mathrm{~nm}$. The shoulder to the Soret-band in $\mathbf{1}$ is bathochromically shifted by approximately $2200 \mathrm{~cm}^{-1}$ compared to ruthenium phthalocyanines with pyridine derivatives as axial ligands.

Generally the Q-band of ruthenium naphthalocyanine complexes is significantly bathochromically shifted compared to the phthalocyanine derivative bearing the same axial ligands, while the Soret-band remains at a similar energy. ${ }^{[16,20]}$ Consistent with this observation the Q-band of $\mathbf{2}$ is bathochromically shifted by 1586 $\mathrm{cm}^{-1}$ compared to that of $\mathbf{1}$. Unusually the Soret-band experiences an even larger bathochromic shift of $3590 \mathrm{~cm}^{-1}$. 


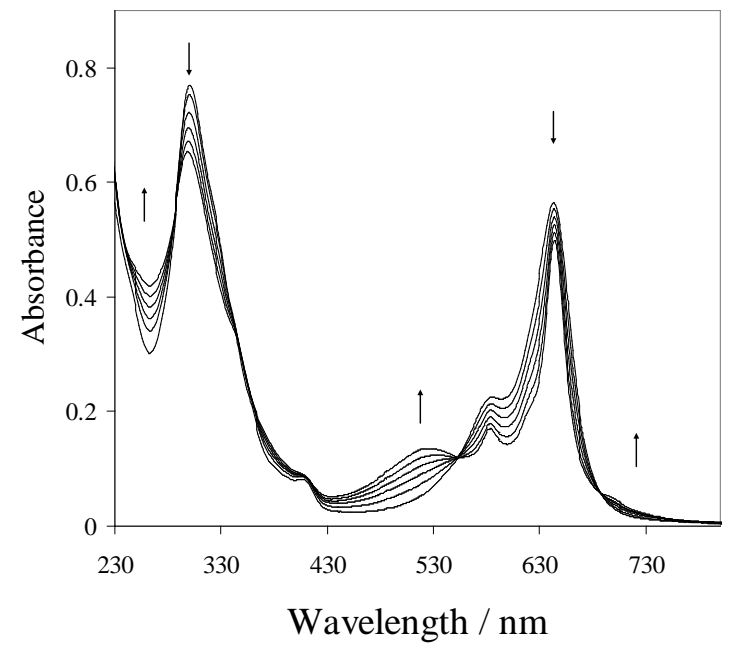

Figure 5. UV-Visible spectra of $\mathbf{1}$ in dichloromethane recorded over 1 hour upon exposure to air.

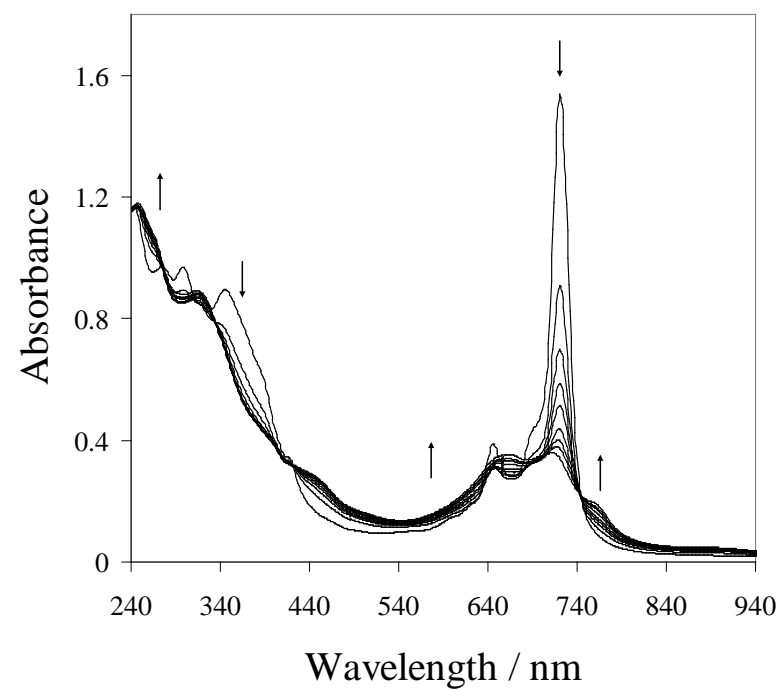

Figure 6. UV-Visible spectra of $\mathbf{2}$ in dichloromethane recorded over 1 hour after exposure to air.

Figures 5 and 6 show the changes in the UV-visible spectra of dichloromethane solutions of $\mathbf{1}$ and $\mathbf{2}$ in air over a period of one hour. Observed is the incomplete replacement of the Q-band of $\mathbf{1}$ by a broad absorption at $525 \mathrm{~nm}$. The Soret-band also reduces in intensity and shifts to higher energy. Isosbestic points are observed suggesting a clean transformation of $\mathbf{1}$ into a single new species. The changes are fully consistent with ring-centred one-electron oxidation to afford a $\left[\mathrm{PcRu}(\mathrm{L})_{\mathrm{x}}\right]^{+}$species. ${ }^{[31,33,34]}$

In Figure 6, the Q-band of $\mathbf{2}$ and it's shoulder rapidly diminishes in intensity, and a broad absorption at $664 \mathrm{~nm}$ appears. The Soretband also decreases in intensity and a band at $316 \mathrm{~nm}$ appears. These changes are very similar to those observed in Figure 5 and can therefore be assigned to oxidation of the naphthalocyanine ring. The oxidation of $\mathbf{2}$ occurs more rapidly: in one hour oxidation of $\mathbf{2}$ is almost complete while in the same time period $88 \%$ of $\mathbf{1}$ remains un-oxidised.

As shown by ${ }^{1} \mathrm{H}$ NMR, in dimethyl sulfoxide the $\mathrm{AsPh}_{3}$ ligands of both complexes completely dissociate to give the bis(dmso) adducts. When the electronic spectrum of $\mathbf{2}$ was recorded in dimethyl sulfoxide the spectral changes attributed to oxidation did not occur. The bis(dmso) complex was completely stable over five hours. These results immediately suggests that at least one axial arsine ligand must remain for an oxidation reaction with dioxygen to proceed.

That dioxygen is the oxidant was confirmed by deoxygenating the solvent using repeated freeze / pump / thaw cycles. The rate of oxidation was dramatically reduced. An additional observation is that the rate of oxidation was also inhibited by adding a 50 fold excess of $\mathrm{AsPh}_{3}$ to the solution. This suggests dissociation of an axial arsine may be important in the reaction with dioxygen.

Two different routes may be proposed for the which oxidation of $\mathbf{1}$ and $\mathbf{2}$ may occur:

$$
\begin{aligned}
& {\left[\mathrm{Mc}^{2-} \mathrm{Ru}^{\mathrm{II}} \mathrm{L}_{2}\right] \rightleftarrows\left[\mathrm{Mc}^{2-} \mathrm{Ru}^{\mathrm{II}} \mathrm{L}\right]+\mathrm{L} \rightarrow\left[\mathrm{Mc}^{-} \mathrm{Ru}^{\mathrm{II}} \mathrm{L}\right]^{+}+\mathrm{L}} \\
& {\left[\mathrm{Mc}^{2-} \mathrm{Ru}^{\mathrm{II}} \mathrm{L}_{2}\right] \rightarrow\left[\mathrm{Mc}^{-} \mathrm{Ru}^{\mathrm{II}} \mathrm{L}_{2}\right]^{+} \rightleftarrows\left[\mathrm{Mc}^{-} \mathrm{Ru}^{\mathrm{II}} \mathrm{L}\right]+\mathrm{L}}
\end{aligned}
$$

In equation (1) one $\mathrm{AsPh}_{3}$ ligand dissociates, forming a fivecoordinate species, which is readily oxidised. The formation of a five-coordinate species is possible. As already described, the ${ }^{1} \mathrm{H}$ NMR spectra of $\mathbf{1}$ and $\mathbf{2}$ showed the $\mathrm{AsPh}_{3}$ ligands to be labile, and five coordinate ruthenium phthalocyanine and naphthalocyanine complex are already known. For example, the complex $\mathrm{K}_{2}\left[\mathrm{PcRu}\left\{\mathrm{Ph}_{2} \mathrm{P}\left(3-\mathrm{C}_{6} \mathrm{H}_{4} \mathrm{SO}_{3}\right)\right\}_{2}\right]$ dissociates in solution to form a stable five coordinate species, ${ }^{[24]}$ while the naphthalocyanine derivative $^{[17]}$ is isolated as a five coordinate complex. Arsine and phosphine ligands have similar trans effects. The formation of dimeric complexes by loss of both axial ligands can be ruled out. The $\left[\left\{(t \mathrm{Bu})_{4}-2,3-\mathrm{NcRu}\right\}_{2}\right]$ dimer is insoluble in organic solvents, ${ }^{[30]}$ and clearly the species being oxidised in Figure 6 is soluble with no precipitate observed during any of these experiments. Furthermore $\left[(\mathrm{PcRu})_{2}\right]^{[35]}$ and $\left[\left\{(t \mathrm{Bu})_{4} \mathrm{PcRu}\right\}_{2}\right]^{[30]}$ interact with oxygen forming a species with a Q-band of increased intensity, which is not the case here. From equation (1) the impairment of the oxidation rates with excess $\mathrm{AsPh}_{3}$ can be explained by forcing the equilibrium back to the more stable six coordinate complexes.

In equation (2), the macrocycle is first oxidised, presumably in an outer-sphere reaction with dioxygen, followed by loss of an axial ligand. The two electron-donating $\mathrm{AsPh}_{3}$ ligands should make oxidation of the macrocycles occur more readily in this case. This is demonstrated by the relatively low potential at which both complexes undergo the first oxidation. The effect of excess $\mathrm{AsPh}_{3}$ on the oxidation rate in this scenario would be to act as a sacrificial reductant, forming $\mathrm{AsPh}_{3}=\mathrm{O}$ and regenerating $\left[\mathrm{Mc}^{2-} \mathrm{Ru}\left(\mathrm{AsPh}_{3}\right)_{2}\right]$ (i.e. $\mathbf{1}$ and $\mathbf{2}$ from $\mathbf{1}^{+}$and $\mathbf{2}^{+}$).

\section{Conclusions}

We have prepared the first examples of metallo phthalocyanine and naphthalocyanine complexes with axial arsine ligands. The $\mathrm{AsPh}_{3}$ ligands are labile in both complexes although moreso in the naphthalocyanine example.

Cyclic voltammetry revealed one reduction and two oxidation processes for the phthalocyanine derivative, similar to ruthenium 
phthalocyanine complexes with pyridyl axial ligands albeit at somewhat different potentials. The naphthalocyanine derivative undergoes one reduction and three oxidations. The reduction and first oxidation are assigned to macrocycle centred processes. The UV-Vis spectra of both complexes recorded over time showed macrocycle-centred oxidation caused by dissolved oxygen. We were not able to determine if the species being oxidised are the starting complexes, or if ligand dissociation leads to an easily oxidised five coordinate species. The lability of the arsine ligands may hinder use of these complexes in applications. Nevertheless, the arsine complexes show significant differences in properties of previously reported pthalocyanine and napphalocyanine ruthenium derivatives.

\section{Experimental Section}

\section{Experimental}

\section{General}

${ }^{1} \mathrm{H}$ NMR spectra were recorded using a BVT 3000 Bruker Spectrospin instrument operating at $300.13 \mathrm{MHz}$. Spectra are referenced internally to residual protic solvent $\left(\mathrm{CHCl}_{3}, \delta\right.$ 7.26). $\mathrm{UV}$-visible spectra of dichloromethane solutions were recorded using an Agilent 8453 UV-Visible spectrophotometer. Infra-red spectra were recorded using a Nicolet Magna IR-760 spectrometer with complexes dispersed in $\mathrm{KBr}$ discs. Electrospray ionization mass spectra (ESI-MS) were recorded using a Perkin-Elmer SCIEX API300 Triple Quadrupole Mass Spectrometer. The general conditions were: ion spray voltage $=5000 \mathrm{~V}$, drying gas temperature $=50{ }^{\circ} \mathrm{C}$, orifice voltage $=30 \mathrm{~V}$, ring voltage $=340 \mathrm{~V}$, and injection via syringe pump. Spectra were averaged over 10 scans. Elemental microanalyses were carried out by the Microanalytical Service Unit at the Research School of Chemistry, Australian National University. We note that the C-analyses are consistently lower than the calculated values; a trend found in other reported microanalytical data for ruthenium phthalocyanine complexes.

Cyclic voltammetry measurements were performed in a conventional three electrode cell using a computer-controlled Pine Instrument Co. AFCBP1 bipotentiostat as described in detail elsewhere. ${ }^{[36]}$ The compounds were dissolved in dichloromethane (distilled over phosphorus pentoxide before use) with $0.1 \mathrm{M}$ [ $n$ $\left.\mathrm{Bu}_{4} \mathrm{~N}\right]\left[\mathrm{PF}_{6}\right]$ as supporting electrolyte. The solutions were sparged with dry nitrogen gas before each measurement. Cyclic voltammograms were recorded with a $0.5 \mathrm{~mm}$ glassy carbon working electrode at scan rates ranging from 50 to $2000 \mathrm{mV} \mathrm{s}^{-1}$. The potentials in this paper are quoted relative to the ferrocenium, ferrocene $\left(\mathrm{Fe}^{\mathrm{III}}, \mathrm{Fe}^{\mathrm{II}}\right)$ couple measured under identical experimental conditions, which occurred at $0.49 \mathrm{mV}$ vs. the $\mathrm{Ag}, \mathrm{AgCl}$ reference.

Chemicals. $\left[\left\{(t \mathrm{Bu})_{4}-2,3-\mathrm{Nc}\right\} \mathrm{Ru}(\mathrm{NCPh})_{2}\right]$ was prepared by a modified literature procedure ${ }^{[24]}$ from 6-t-butyl-2,3-naphthalonitrile (Aldrich). $\quad\left[\mathrm{PcRu}(\mathrm{PhCN})_{2}\right]^{[24]}$ were prepared by literature procedures. The following were purchased commercially and used as received; $\mathrm{RuCl}_{3} \cdot 3 \mathrm{H}_{2} \mathrm{O}$ (Precious Metals Online), $n$-pentanol (Aldrich), hydroquinone (Aldrich), benzonitrile (Aldrich), and triphenylarsine (Aldrich).

\section{Synthesis}

Preparation of $\left[\mathrm{PcRu}\left(\mathrm{AsPh}_{3}\right)_{2}\right] \quad$ 1. To a deoxygenated dichloromethane solution $(60 \mathrm{~mL})$ of $\left[\mathrm{PcRu}(\mathrm{PhCN})_{2}\right](200 \mathrm{mg}$, $0.24 \mathrm{mmol}$ ) was added triphenylarsine (224 $\mathrm{mg}, 0.73 \mathrm{mmol}$ ). The resulting solution was heated at reflux for $4 \mathrm{~h}$ under a nitrogen atmosphere. After cooling to room temperature the solvent was removed using a rotary evaporator. The resulting solid was dissolved in dichloromethane $(80 \mathrm{~mL})$ and filtered. Hexane (240 $\mathrm{mL}$ ) was added and the suspension was left to sit for 15 hours. The precipitated $\left[\mathrm{PcRu}\left(\mathrm{AsPh}_{3}\right)_{2}\right.$ ] was collected by filtration and washed with hexane. A second crop of $\left[\mathrm{PcRu}\left(\mathrm{AsPh}_{3}\right)_{2}\right]$ was collected by reducing the volume of the filtrate to $160 \mathrm{~mL}$. Both crops were combined and dried in vacco at $100{ }^{\circ} \mathrm{C}$ overnight, yielding $151 \mathrm{mg}$ (51\%) of $\left[\mathrm{PcRu}\left(\mathrm{AsPh}_{3}\right)_{2}\right] \cdot 0.125 \mathrm{CH}_{2} \mathrm{Cl}_{2}$ as a blue solid. ${ }^{1} \mathrm{H} \mathrm{NMR}$ (300 MHz, $\mathrm{CDCl}_{3}, 27^{\circ} \mathrm{C}$ ): 8.95 (m, $8 \mathrm{H}, \mathrm{Pc}$ ), 7.81 (m, $8 \mathrm{H}, \mathrm{Pc}$ ), $6.69\left(\mathrm{t}, J_{\mathrm{HH}}=7.5 \mathrm{~Hz}, 6 \mathrm{H}, \mathrm{Ph}\right), 6.32\left(\mathrm{t}, J_{\mathrm{HH}}=7.6 \mathrm{~Hz}, 12 \mathrm{H}, \mathrm{Ph}\right)$, $5.30\left(\mathrm{~s}, 0.25 \mathrm{H}, \mathrm{CH}_{2} \mathrm{Cl}_{2}\right) 4.59$ (d, $\left.J_{\mathrm{HH}}=6.9 \mathrm{~Hz}, 12 \mathrm{H}, \mathrm{Ph}\right) . \mathrm{IR}\left(\mathrm{cm}^{-}\right.$ $\left.{ }^{1}\right)$ : 3045 (s), 2924 (w), 1639 (m), 1604 (m), 1573 (m), 1487 (vs), 1433 (s), 1410 (s), 1332 (s), 1285 (s), 1169 (s), 1122 (vs), 1064 (s), 1025 (mw), 998 (mw), 967 (w), $944(\mathrm{w}) 905(\mathrm{mw}), 866(\mathrm{w}), 847$ (w), 777 (m), 735 (s), 734 (vs), 691 (s), 614 (w), 575 (mw), 505 (w), 478 (s), 439 (mw). UV-vis $\left(\lambda_{\max }, \mathrm{nm}\left[\varepsilon, 10^{3} \mathrm{M}^{-1} \mathrm{~cm}^{-1}\right]\right): 643$ [58], 584sh, 409sh, 303 [78]. MS ( $/ \mathrm{m} / \mathrm{z}): 1227\left([\mathrm{M}+\mathrm{H}]^{+}, 100\right)$. Anal. Calcd for $\mathrm{C}_{68.125} \mathrm{H}_{46.25} \mathrm{~N}_{8} \mathrm{Cl}_{0.25} \mathrm{As}_{2} \mathrm{Ru}$ : C 66.61, H 3.48, N 9.14. Found: C 66.16, H 3.77, N 9.06.

A singlet at $\delta 5.30$ arises from dichloromethane, which could not be removed even under high vacuum at $100{ }^{\circ} \mathrm{C}$ so must be incorporated into the crystal lattice.

Preparation $\left[\left\{(t \mathrm{Bu})_{4}-2,3-\mathrm{Nc}\right\} \mathrm{Ru}\left(\mathrm{AsPh}_{3}\right)_{2}\right]$ 2. To a deoxygenated dichloromethane solution $(40 \mathrm{~mL})$ of the crude $\left[\left\{(t \mathrm{Bu})_{4}-2,3-\right.\right.$ $\mathrm{Nc}\} \mathrm{Ru}(\mathrm{PhCN})_{2}$ ] (200 mg, $\left.0.16 \mathrm{mmol}\right)$ was added triphenylarsine (148 $\mathrm{mg}, 0.48 \mathrm{mmol}$ ). The resulting solution was heated at reflux for $4 \mathrm{~h}$ under a nitrogen atmosphere. After cooling to room temperature the solvent was removed using a rotary evaporator. The crude product was purified by silica column chromatography eluting with dichloromethane:hexane (9:1). The resulting solid was suspended in methanol, and the solid was collected by filtration and washed with methanol. $40 \mathrm{mg}(15 \%)$ of $\left[\left\{(t \mathrm{Bu})_{4}-2,3-\right.\right.$ $\mathrm{Nc}\} \mathrm{Ru}\left(\mathrm{AsPh}_{3}\right)_{2}$ ] was collected as a green powder. ${ }^{1} \mathrm{H}$ NMR (300 $\mathrm{MHz}, \mathrm{CDCl}_{3}, 2{ }^{\circ} \mathrm{C}$ ): 9.47 (s, $4 \mathrm{H}, \mathrm{Nc}$ ), 9.43 (s, $4 \mathrm{H}, \mathrm{Nc}$ ), 8.40 (m, $8 \mathrm{H}, \mathrm{Nc}), 7.87$ (m, 4H, Nc), $6.62\left(\mathrm{t}, J_{\mathrm{HH}}=6.9 \mathrm{~Hz}, 6 \mathrm{H}, \mathrm{Ph}\right), 6.27(\mathrm{t}$, $\left.J_{\mathrm{HH}}=7.8 \mathrm{~Hz}, 12 \mathrm{H}, \mathrm{Ph}\right), 4.74\left(\mathrm{~d}, J_{\mathrm{HH}}=7.2 \mathrm{~Hz}, 12 \mathrm{H}, \mathrm{Ph}\right), 1.66(\mathrm{~m}$, $36 \mathrm{H}, t-\mathrm{Bu})$. IR ( $\left.\mathrm{cm}^{-1}\right)$ : 3052 (s), 2955 (vs), 2905 (s), 2866 (s), 1953 (mw), 1616 (m), 1499 (s), 1476 (s), 1460 (m), 1433 (s), 1375 (s), 1371 (vs), 1332 (m), 1317 (m), 1270 (m), 1258 (m), 1204 (mw), 1184 (m), 1165 (s), 1142 (s), 1111 (vs), 1087 (m), 1041 (m), 1017 (mw), $994(\mathrm{mw}), 951(\mathrm{mw}), 897(\mathrm{~m}), 847(\mathrm{w}), 812(\mathrm{mw}), 742(\mathrm{~s})$, 691 (s), 664 (mw), $641(\mathrm{mw}), 614(\mathrm{w}), 559(\mathrm{w}), 513(\mathrm{mw}), 474$ (s), 419 (w). UV-vis $\left(\lambda_{\max }, \mathrm{nm}\left[\varepsilon, 10^{3} \mathrm{M}^{-1} \mathrm{~cm}^{-1}\right]\right): 716$ [117], 644sh, 418sh, 340 [83]. MS (m/z): $1650\left([\mathrm{M}]^{+}, 100\right)$. Anal. Calcd for $\mathrm{C}_{100} \mathrm{H}_{86} \mathrm{~N}_{8} \mathrm{As}_{2} \mathrm{Ru}$ : C 72.76, H 5.25, N 6.79. Found: C 71.60, H 5.53, N 6.69 .

Supporting Information (see footnote on the first page of this article): ...

\section{Acknowledgments}

ARC APD

\section{References}

[1] P. Charlesworth, T. G. Truscott, R. C. Brooks,B. C. Wilson, J Photoch. Photobio. B 1994, 26, 277-82.

[2] M. J. Abrams, Platinum Met. Rev. 1995, 39, 14-18.

[3] M. K. Nazeeruddin, R. Humphry-Baker, M. Grätzel,B. A. Murrer, Chem. Commun. 1998, 719-720. 
[4] M. Yanagisawa, F. Korodi, J. He, L. Sun, V. Sundstrom,B. Akermark, J. Porphyrins Phthalocyanine 2002, 6, 217-224.

[5] M. Yanagisawa, F. Korodi, J. Bergquist, A. Holmberg, A. Hagfeldt, B. Akermark,L. Sun, J. Porphyrins Phthalocyanine 2004, 8 , 1228-1235.

[6] K. J. Balkus, Jr., M. Eissa,R. Lavado, Stud. Surf. Sci. Catal. 1995, 94, 713-19.

[7] M. Bressan, N. Celli, N. d'Alessandro, L. Liberatore, A.

Morvillo,L. Tonucci, J. Organomet. Chem. 2000, 593-594, 416-420.

[8] M. Bressan, N. d'Alessandro, L. Liberatore,A. Morvillo, Coord. Chem. Rev. 1999, 185-186, 385-402.

[9] M. Ebadi, C. Alexiou,A. B. P. Lever, Can. J. Chem 2001, 79, 992-1001.

[10] J. A. R. Van Veen, J. F. Van Baar,K. J. Kroese, J. Chem. Soc. Farad. Trans. 1 1981, 77, 2827-43. 293-303.

[11] B. V. Romanovsky,A. G. Gabrielov, J. Mol. Catal. 1992, 74

[12] L. J. Boucher, E. J. Dadey,D. R. Spears, Proc. - Int. Conf. Coal Sci. 1983, 763-6.

[13] H.-H. Liu, Y. Wang, Y.-J. Shu, X.-G. Zhou, J. Wu,S.-Y. Yan, J. Mol. Catal. A: Chem. 2006, 246, 49-52.

[14] A. Generosi, B. Paci, V. R. Albertini, P. Perfetti, A. M. Paoletti, G. Pennesi, G. Rossi,R. Caminiti, Appl. Phys. Lett. 2006, 88, 104106/1-104106/3.

[15] J. Pohmer, M. Hanack,J. Osio Barcina, J. Mater. Chem. 1996, $6,957-962$.

[16] S. Knecht, R. Polley,M. Hanack, Appl. Organomet. Chem. 1996, 10, 649-660.

[17] J. F. Vollano, G. E. Bossard, S. A. Martellucci, M. C. Darkes, M. J. Abrams,R. C. Brooks, J. Photoch. Photobio. B 1997, 37, 230-235.

[18] M. Hanack,R. Polley, Inorg. Chem. 1994, 33, 3201-4.

[19] T. Rawling, H. Xiao, S.-T. Lee, S. B. Colbran,A. McDonagh, Inorg. Chem. 2007, Article in press.
[20] T. Rawling,A. McDonagh, Coord. Chem. Rev., 10.1016/j.ccr.2006.09.011. 347-56.

[21] M. Hanack, U. Keppeler,H. J. Schulze, Synth. Met. 1987, 20, $115-18$.

22] M. Massoudipour,K. K. Pandey, Inorg. Chim. Acta 1989, 160,

[23] M. H. Barley, D. Dolphin,B. R. James, J. Chem. Soc., Chem. Commun. 1984, 1499-500.

[24] G. E. Bossard, M. J. Abrams, M. C. Darkes, J. F. Vollano,R. C. Brooks, Inorg. Chem. 1995, 34, $1524-7$.

[25] M. M. Doeff,D. A. Sweigart, Inorg. Chem. 1981, 20, 1683-7.

[26] W. Kobel,M. Hanack, Inorg. Chem. 1986, 25, 103-7.

[27] F. Pomposo, D. Carruthers,D. V. Stynes, Inorg. Chem. 1982, $21,4245-8$

[28] A. Bulatov, S. Knecht, L. R. Subramanian,M. Hanack, Chem. Ber. 1993, 126, 2565-6.

[29] M. Hanack,Y. G. Kang, Chem. Ber. 1991, 124, 1607-12.

33.

[30] M. Hanack, S. Knecht, R. Polley, Chem. Ber. 1995, 128, 929-

[31] D. Dolphin, B. R. James, A. J. Murray,J. R. Thornback, Can. J. Chem 1980, 58, 1125-32.

[32] K. Durr,M. Hanack, J. Porphyrins Phthalocyanine 1999, 3, 224-229.

[33] T. Nyokong, Polyhedron 1993, 12, 375-81.

[34] T. Nyokong, Z. Gasyna,M. J. Stillman, Inorg. Chim. Acta 1986, 112, 11-15.

[35] A. Capobianchi, A. M. Paoletti, G. Pennesi, G. Rossi, R. Caminiti,C. Ercolani, Inorg. Chem. 1994, 33, 4635-40.

[36] S. B. Sembiring, S. B. Colbran,D. C. Craig, J. Chem. Soc., Dalton Trans. 1999, 1543-1554. 